\title{
Uma casa para D. Quixote (de Coimbra)
}

Filipa Malva
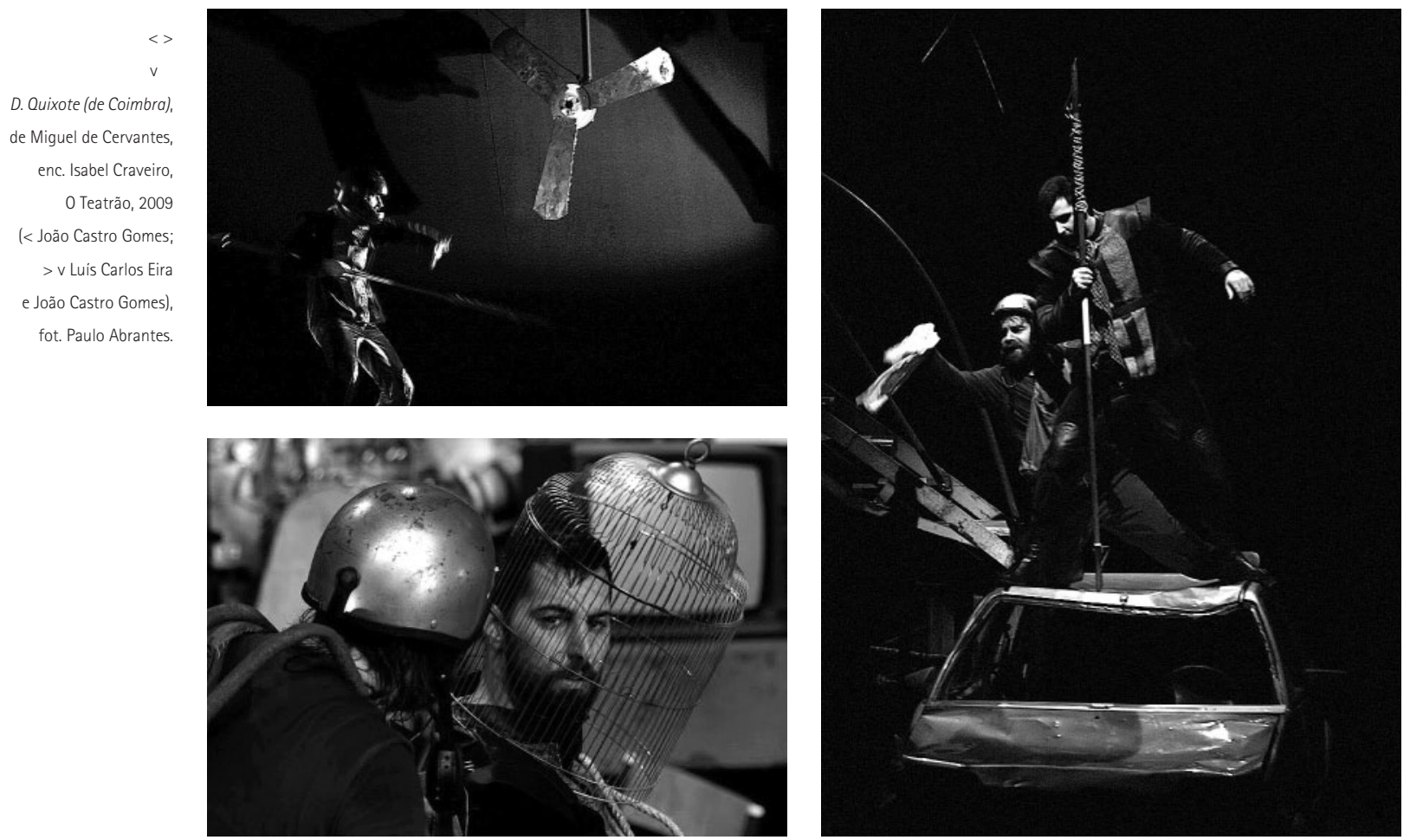

Título: D. Quixote (de Coimbra). Autor: Miguel de Cervantes. Dramaturgia: Jorge Louraço Figueira. Encenação: Isabel Craveiro. Dispositivo cénico e figurinos: Helena Guerreiro. Desenho de luz: Jonathan Azevedo. Música original: Afonso Rodrigues e Filipe da Costa. Interpretação: Inês Mourão, João

Filipa Malva

é cenógrafa e doutoranda em Estudos

Artísticos

(Especialização em

Estudos Teatrais e

Performativos) na

Faculdade de Letras da

Universidade $\mathrm{d}$

Coimbra. Licenciada em

Arquitectura

(Universidade Técnica

de Lisboa, 2001),

é ainda titular de um

Mestrado em

"Performance Space and 1.T. Modelling (University of Kent, Canterbury, 2005) Castro Gomes, Luis Campos Eiras e Margarida Sousa. Produção: 0 Teatrão. Local e data de estreia: Oficina Municipal do Teatro, Coimbra, 19 de Novembro de 2009

D. Quixote (de Coimbra) esteve em cena na Oficina Municipal do Teatro, entre Novembro de 2009 e Janeiro de 2010. Durante duas horas, o público foi convidado a partilhar as aventuras de D. Quixote e seu fiel companheiro Sancho Pança, segundo a dramaturgia de Jorge Louraço Figueira e a encenação de Isabel Craveiro.

A sedução da vida errante e idealista de D. Quixote de la Mancha tem ocupado o nosso imaginário desde a publicação do primeiro volume. Os ideais de justiça e lealdade, que caracterizam o romance de cavalaria, transformam e submetem D. Quixote, fazendo do velho senhor um líder destemido que defende a honra das donzelas e a vida dos mais fracos. São estes mesmos romances que Cervantes tenta criticar, quando apresenta a sua personagem principal como um louco, habitando o limite da sociedade. 0 contraste entre a vida calma e realista de Sancho Pança e as vontades imprevisíveis de
D. Quixote dá origem a longas conversas. 0 primeiro deixase seduzir, ocasionalmente, pelo imaginário e pelas recompensas de uma vida de escudeiro; o segundo entende as advertências de Sancho como detalhes insignificantes na sua narrativa idealista.

Tal como em D. Quijote de Orson Welles (1992), são também estas conversas que estão no centro das atenções e da interpretação proposta pel'O Teatrão. Sancho prefere as coisas reais e simples, comer pouco mas sem cortesias, vida simples de camponês, família e terra para arar. Mas muitas vezes deixa-se arrastar pelas fantasias de D. Quixote particularmente no que toca à sua ambição por dinheiro comida e terras. Não deixa nunca de the ser fiel, mesmo se para isso o tenha que enganar. Se a personagem de $D$. Quixote pode carregar consigo toda uma visão da sociedade cortês, a de Sancho Pança representa o seu contraponto. Não poderia existir uma sem a outra (contrapontos até 


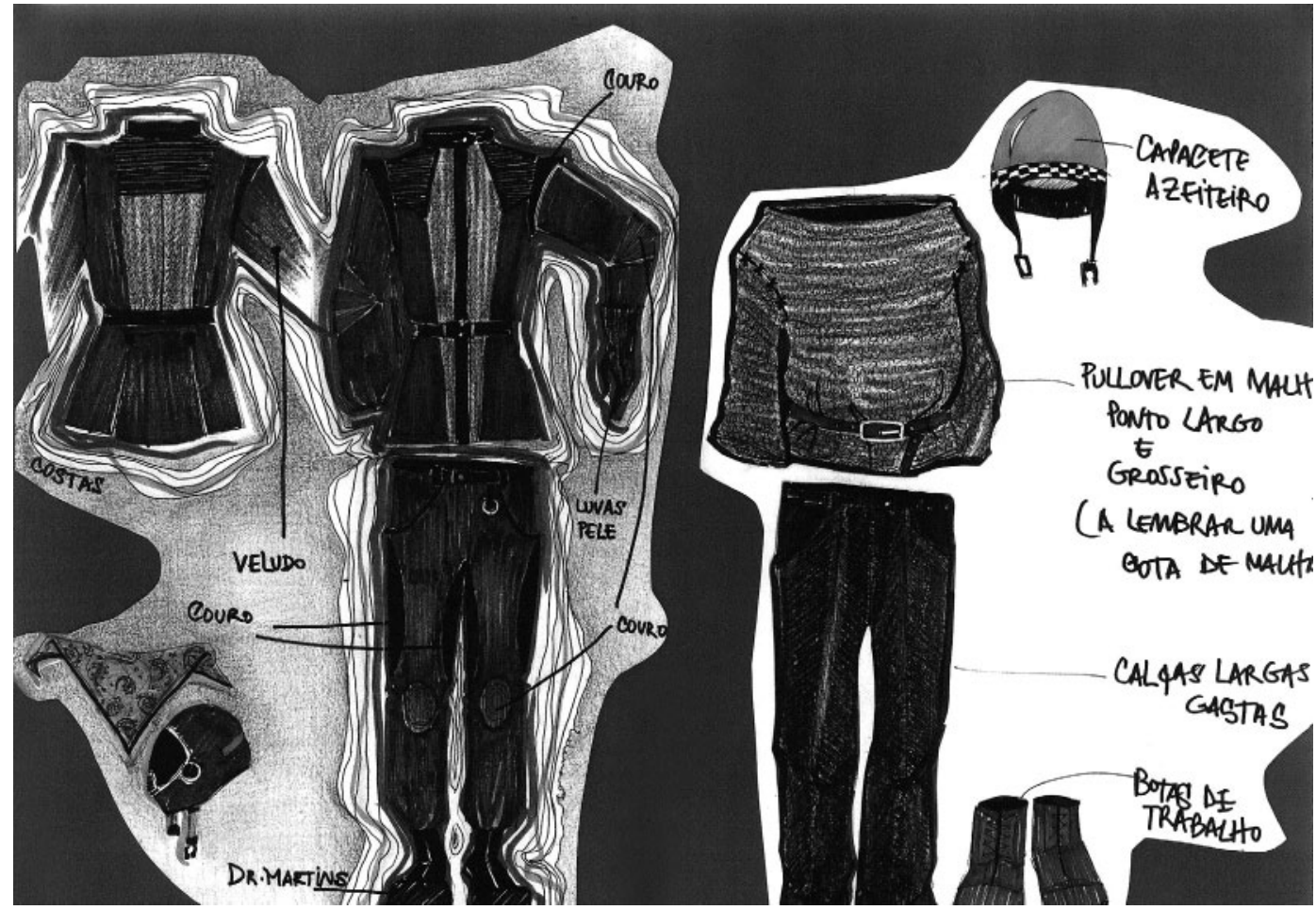

nos figurinos: o homem de lã, áspera mas moldável, e o de cabedal ou de ferro, duradouro e usado), emprestando Sancho a sensatez do dia-a-dia e D. Quixote a capacidade de ver para além do palpável. As duas personagens são indissociáveis em termos dramáticos já que possibilitam, pelas suas acções conjuntas e contrastantes, o desenrolar da história. Elas fazem avançar a narrativa, introduzem personagens secundárias e exploram o espaço e o tempo cenográficos. De algum modo, Sancho e D. Quixote tornamse narradores de tudo o que não é encenado directamente, completando assim o mundo ficcional em que vivem. As outras personagens são muitas vezes apenas pretextos para longas conversas entre eles, durante as quais dois pontos de vista são aceites, por vezes mesmo sem concordância. A sua relação é também a origem da muito interessante comédia física que se desenvolve perante o nosso olhar.

Também na versão inacabada do filme de Orson Welles, acima referido, há uma cena em que D. Quixote e Sancho assistem a uma sessão de cinema, um filme de cowboys. Depois de Sancho partilhar um chupa-chupa com uma menina loura no público, D. Quixote, incomodado pela carga de cavalaria que se vê, dirige-se ao ecrã e desfá-lo em pedaços, numa tentativa vã de atacar os cavaleiros; o público grita e refila. A diferença de escala entre $D$. Quixote e as personagens no ecrã, o facto de o público enfurecido ver a sua tarde de cinema arruinada, diz muito sobre o ponto de vista de Orson Wells relativamente à obra de Cervantes. Quando D. Quixote rasga o ecrã, os "moinhos de vento", que acreditamos serem verdadeiros naquele momento, transformam-se em farrapos de tela, quebrando a ilusão da sétima arte, definindo assim a falha irrecuperável entre a realidade das outras personagens e ele próprio: Sancho é o único elo de ligação entre os dois mundos. Em Coimbra, D. Quixote ataca um carrinho de compras que transporta o inimigo e derrota-o em luta feroz; vive-se uma sensação de tristeza e mesmo Sancho acredita que o seu amo está realmente em apuros: para o público de teatro, um carrinho de compras pode bem ser o cavalo mais feroz do universo. 0 Teatrão apresenta um mundo em contraste com a sua personagem principal, que acaba por se deixar transformar - bem como as suas personagens, o espaço e o tempo narrativo - num universo onde vive a imaginação louca de D. Quixote. Esta 


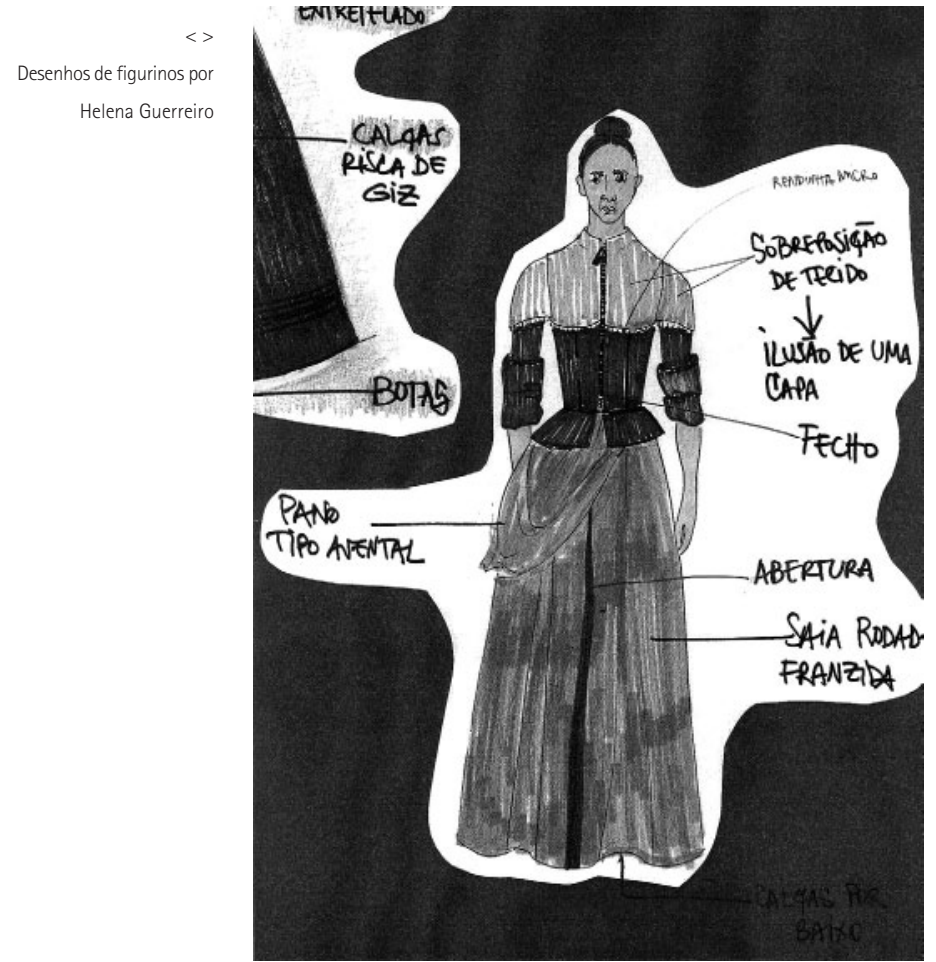

solidariedade ficcional estende-se ao lado físico da encenação.

Um cenário em dois andares com um portão de lata que abre sobre um tapete azul; um carro prensado; degraus feitos de cadeiras metálicas e uma ponte-levadiça que permite aos actores correr e saltar, atacar os vilões que surgem entre o público. E também inúmeros Rocinante(s): uma mota, um carro de compras e, no fim, um cavalo de pau feito de entranhas mecânicas, transportam D. Quixote através das terras de Espanha e Coimbra.

0 trabalho de Helena Guerreiro, responsável pelo cenário e figurinos, é louvável na sua capacidade de trazer para a contemporaneidade o imaginário de Cervantes. É um cenário feito da adição de objectos muito específicos do nosso dia-a-dia, uma colecção que pode ser vista à beira de muitas estradas portuguesas. Um refugo que não tem nada de aleatório, já que cada um dos adereços tem uma função narrativa muito específica. A cenografia usa o imaginário ilimitado da personagem de D. Quixote como licença para mudanças repentinas de escala (por exemplo, a jaula onde Sancho o carrega é apenas uma pequena gaiola), utilização simbólica de cor (o tapete azul, cor que

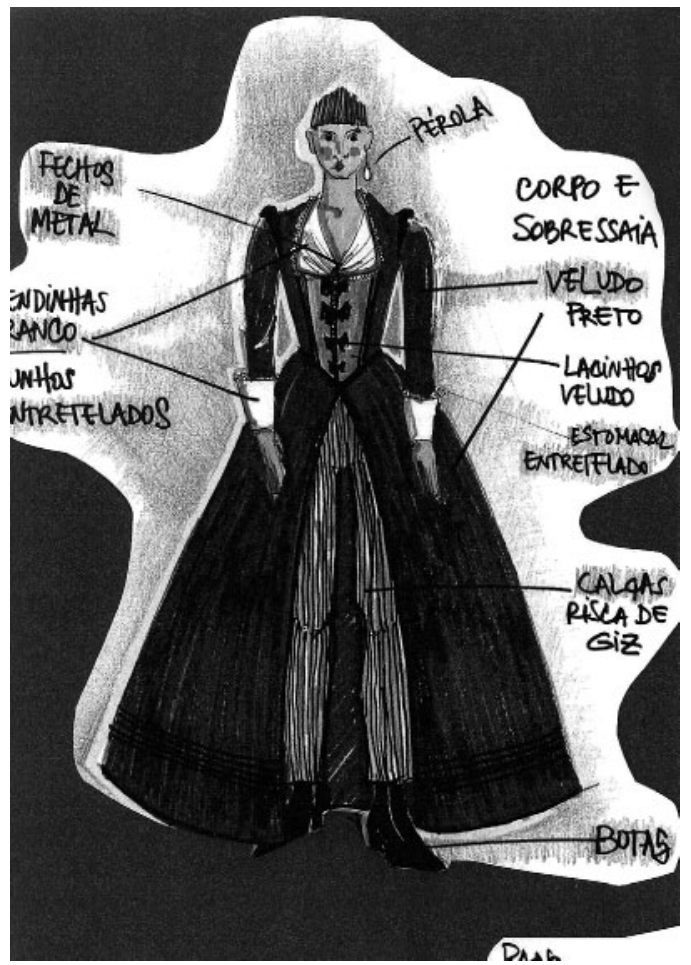

prossegue o discurso de D. Quixote), ou construção de figurinos multifacetados (as personagens da sobrinha e da governanta transformam-se num rol de vilãos). Como se escreve no programa do espectáculo, o uso de objectos velhos e usados obriga a agir para que os tornem vigorosos, origem de um movimento fluído de futuro. Desse ponto de vista, esta cenografia e a sua relação com a encenação é fundamental na conversão do texto de Cervantes: a conversão de uma peça sobre a loucura de um velho desiludido numa história de esperança.

Será a mudança da idade da personagem de D. Quixote importante? No original, é um senhor de meia-idade que vive nos romances de cavalaria e que antes de morrer renuncia aos seus ideais, aceitando a loucura. Nesta versão, D. Quixote é um jovem adulto, com cerca de 30 anos, cuja loucura é fruto de uma vontade indómita de mudar o mundo, arrastando (convencendo) todas as outras personagens para um imaginário cavalo de pau voador na cena final. Se o homem velho acentuava a reflexão sobre uma sociedade perdida num passado idealizado, 0 homem novo e o final aberto sugerem uma geração que, embora fantasista, poderá transformar pela própria 
capacidade de sonhar uma sociedade acomodada e pejada de objectos inúteis. Do mesmo modo, o declínio físico de D. Quixote, bem evidente no original, não é de todo claro na peça. 0 climax narrativo produzido pela morte final e todas as cenas que o prevêem, desaparecem para dar lugar a uma narrativa cíclica e centrípeta que acaba por envolver todos os presentes. Para além da comédia e de um fim desiludido e triste, momento em que a personagem principal aceita as regras do mundo convencional (tal como o original de Cervantes ou a versão de António José da Silva), 0 Teatrão vai buscar o final aberto, sugerido por Monteiro Lobato na sua versão infantil (Lobato: 1936): e se D. Quixote não morresse, e se a sua loucura fosse mais lúcida que a realidade de Sancho, que sonha com uma casa para além do monte de refugo, da adição sempre incompleta de objectos encontrados?

Para um público de crianças (muito embora o espectáculo esteja classificado para o público geral), é natural aceitarmos a fantasia de D. Quixote. Do mesmo modo que este foge à realidade, resistindo às investidas da sociedade em que vive, o público infantil vê a sua história imaginária como um direito de herói. As regras sociais que este evita e ignora são regras de um mundo paralelo adulto. As crianças vivem entre este último e a evasão do maravilhoso, aceitando o equilíbrio entre ambos. Serão por isto mesmo, um público ideal. Quando uma criança desenha, aquilo que cria apoia-se na realidade, mas rege-se por relações próprias, internas. Estas regras são relevantes apenas porque dão sentido à composição, delineando um todo, que pode parecer deslocado da realidade exterior. É também esta capacidade de entender os princípios que regem uma história para além dos limites da normalidade que é pedido ao público de D. Quixote (de Coimbra).

Com este objectivo, as luzes são usadas para definir a viagem das personagens entre estes dois mundos, servindo de guia ao público. 0 desenho de luz varia entre tons frios (azul e branco) e tons quentes (vermelho e laranja) a cada momento: sempre que há uma mudança da realidade de Sancho para a de D. Quixote, as cores mudam. Para Sancho, o cenário, a casa do seu senhor e os campos que atravessam, são crus, realistas, plenos de texturas rudes de objectos usados e velhos; ou então escuros, mal iluminados e perigosos. Para D. Quixote, tudo parece ambiguo e aventuroso, com múltiplas projecções. Das sombras aparecem velhos inimigos e vilões destemidos que vêm desafiar o "velho" cavaleiro.

Mas à medida que o espectáculo se aproxima do fim, as tonalidades frias e as sombras assustadoras fundemse para dar lugar a um céu estrelado onde um cavalo de baloiço voa, levando na sua garupa D. Quixote, Sancho, a governanta e a sobrinha.

Este é um final onírico, cheio de esperança. Por uma última vez, D. Quixote tenta convencer os seus companheiros, que voam sobre planicies e mares, e eles deixam-se convencer finalmente.

0 Teatrão escolheu tratar a história de D. Quixote de la Mancha, mostrando a sua relevância para a contemporaneidade, cruzando a avaliação crua do presente com a expectativa de futuro - tal como os objectos usados do cenário descobrem novos significados nas mãos dos actores. 0 dramaturgo Jorge Louraço Figueira optou por um final em aberto, tornando D. Quixote num herói sem descanso, onde a loucura deu lugar à expectativa, ensinando o seu público a lutar contra moinhos de vento.

E isso é tudo o que o teatro pode ser: esperança que nos faz trocar o vulgar quotidiano por um romance de cavalaria.

\section{Referências bibliográficas}

CERVANTES, Miguel de (2007), D. Quixote de la Mancha, trad. José Bento, Relógio D'Ȧgua Editores, Lisboa.

LOBATO, Monteiro, (1936) D. Quixote das Crianças, Circulo do Livro, São Paulo, acedido em Fevereiro de 2010, a partir de:

http://www.scribd.com/doc/2803845/Dom-Quixote-das-Criancas. 